\title{
Games for Empathy for Sensitive Social Groups
}

\author{
https://doi.org/10.3991/ijes.v4i3.5923 \\ Chara Papoutsi, and Athanasios S. Drigas \\ NCSR DEMOKRITOS, Institute of Informatics and Telecommunications, Net Media Lab, Athens, Greece
}

\begin{abstract}
Information and Communication Technology is part of almost everyone's everyday life in a variety of ways and in many fields. All people should have access to ICTs including those with various disabilities and those with health problems. The studies presented in this article represent a body of work outlining positive effects of playing games in the area of special education and health care in order to cultivate empathy.
\end{abstract}

Index Terms-ICTs, Empathy, Emotion Recognition, Games, Special Education, Health

\section{INTRODUCTION}

The presence of information and communication technologies (ICT) in society is an evident reality and an area of special reflection and continuous evolution that has expanded in recent years due to the speed of technological advances and their impact on the world. Especially in healthcare and special education, technologies nowadays have a very important role, and has been proven to be helpful because thanks to their varied pace and combination of graphics, sounds and animation, create a dynamic, attractive and motivating environment for pupils with special educational needs and health problems.

Technology and games have already proven viable and effective for supporting therapy, promoting intercultural communication, increasing understanding of ethnic, religious and historical funded conflicts, and representing different perspectives on issues such as global politics and foreign policy. In addition effects that are aimed to be achieved through games are changes in the knowledge, attitudes, cognitive skills, physical ability, health or mental wellbeing of the user. Furthermore, games are playing a significant role in increasing people's social abilities. One important social skill is empathy.

McDonagh (2006) defines empathy as 'the intuitive ability to identify with other people's thoughts and feelings - their motivations, emotional and mental models, values, priorities, preferences, and inner conflicts' [1].

The construct of empathy originated in 1873 in art history, when Vischer used the term 'Einfühlung' (German for feeling into) to describe a process in which a woman projects her entire personality upon an object, and in some sense merges with this object. The psychologist Theodor Lipps (1851-1914) applied it to explaining aesthetic experiences 'Einfühlung [...] is the fact that the contrast between myself and the object disappears' [2] , and then applied the term to people's experience and knowledge of other people's mental states [3].

As Gallo (1989) puts it: ...an empathic response is one which contains both a cognitive and an affective dimension....the term empathy [is] used in at least two ways; to mean a predominantly cognitive response, understanding how another feels, or to mean an affective communion with the other. Carl Rogers (1975) wrote: ...the state of empathy or being empathic is to perceive the internal frame of reference of another with accuracy and with the emotional components and means which pertain thereto as if one were the person, but without ever losing the æas if condition (Quoted in Gallo 1989) [4].

Difficulties with social interaction, reciprocal communication and emotion recognition are widely acknowledged as key characteristics of individuals diagnosed with an Autism Spectrum Disorder (ASD) or other disabilities. Moreover people with serious health problems often face emotional difficulties or people that surround them lack of empathy for pupils who face health problems. Interaction with digital games increases possibilities of interacting with the environment, thus improving quality of life on the emotional level and increase the possibility of develop empathy and others socioemotional skills.

The current article presents an overview with the most representative studies and focuses on games that have as a primary or secondary aim the detection and cultivation of empathy on important issues. The games have been expanded in the sectors mentioned underneath: Games for Special Education and Games for Health.

\section{GAMES FOR EMPATHY}

\section{A. Games for Special Education}

Schuller et al. (2014) introduced the gaming platform ASC Inclusion targeted to children aged 5 to 10 years with Autistic Spectrum Disorders. The running ASC-Inclusion project aims to help children with ASC by allowing them to learn how emotions can be expressed and recognized via playing games in a virtual world. The platform includes analysis of users' gestures, facial, and vocal expressions using standard microphone and web-cam or a depth sensor, training through games, text communication with peers, animation, video and audio clips [5]

Serret (2012) developed a serious game, "Jestimule", to improve social cognition and empathy in ASD. ICT was also used to facilitate the use of the game by young children or by children with developmental delays (e.g., haptic joystick for feed-back). One of the main aims of the game was to teach ASD individuals to recognize facial emotions, emotional gestures and emotional situations. The game was tested on a group of 40 individuals (aged form 6 to 18) at the hospital. Results showed that participants improved their recognition of facial emotions, emotional gestures and emotional situations in different tasks. These results have clear education and therapeutic implications in ASD and should be taken into account in future training [6].

Alves et al. (2013) presented the "LIFEisGAME" prototype-Ipad version which is a game that promotes facial recognition and helps individuals with ASD to understand 
emotions in order to develop empathy using real-time automatic facial expression analysis and virtual character synthesis. It includes five games modes. "LIFEisGAME" prototype was tested on 11 children with ASD, with ages varying from 5-15 years old and was played during a 15 minute game session. The results were promising and indicated the usefulness of the game to promote emotional understanding, bringing positive outcomes to quality of life for children with autism [7], [8].

Beumont and Sofronoff (2008) developed "The Junior Detective Training Program" an intervention program that included a computer game, small group sessions, parent training sessions and teacher handouts to teach social skills and emotional understanding to children with Asperger syndrome. The computer game was developed such that the user was a detective who specialized in decoding other's mental and emotional states. Playing through different levels, the participants practice recognizing facial expressions, body postures and prosody of speech, in which they learn to recognize complex emotions. Both human and computer-animated characters were utilized to teach emotion recognition and social problem solving. Support and mission outcomes were individualized and varied depending on how a user completed a given task. The study was tested on 49 children with Asperger syndrome between 7.5 and 11 years of age. Overall, findings from this study suggest that the Junior Detective Training Program may be an effective tool for teaching social functioning and emotion recognition to children with Asperger syndrome. However, although components of the intervention were developed specifically to enhance skill generalization, this study did not measure the generalization of targeted skills to real life social contexts [9].

Finkelstein et al. (2009) presented "cMotion", a game in development, which uses virtual characters to reinforce empathy, emotion recognition and logical problem solving to both normally developed children and high-functioning children with autism. "cMotion" consists of a playable introduction which focuses on social skills and emotion recognition, an interactive interface which focuses on computer programming, and a full game which combines the first two stages into one activity [10].

Gibbons (2015) presented "Auti-Sim", a game in prototype stage that simulates what it feels like to have sensory hypersensitivity disorder, the way children with autism do. It was developed during Hacking Health Vancouver 2013 hackathon in 12 hours, by a team of three people. The game puts the player in the shoes of a child with autism in a busy playground, and leaves them to explore this environment on their own and feel empathy for. The player quickly finds that prolonged exposure to sources of sensory stimulation can cause sensory overload, represented in the form of visual noise and blur, as well as audio distortion [11].

University of Southern California (2014) developed "Social Clues", a game with the purpose to teach autistic children about appropriate behaviors and how to change their behavior through activities based on real-world situations and environments. Players take on the role of communiKate or particiPete, learning about the meaning of facial expressions, the importance of eye contact, and the value of empathy [12].

Gerling et al (2014) designed "Birthday Party", a wheelchair-controlled persuasive game in which players have to complete a series of wheelchair-related challenges. The players are controlling an avatar with a wheelchair and the aim is to navigate him in order to arrive at a friend's birthday party on time. On the way, the player has to stop at different locations to pick up items for the party, but the player is running late, so completing all tasks quickly is important. The game evokes empathy and a positive attitude regarding people with disabilities [13].

Pivik et al. (2002) developed "Barriers: The Awareness Challenge", a program used desktop Virtual Reality to simulate the experiences of a child in a wheelchair, in an environment familiar to most children-an elementary school. The program provides opportunities where the child without a disability literally experiences different situations, viewpoints, perceptions, and interactions from the perspective of a child with a disability. The specific objectives of this project were to increase children's knowledge of accessibility and attitudinal barriers that impact individuals with disabilities and to promote more positive attitudes and feelings towards children with disabilities [14].

Ballesta et al. (2011) designed the educational software "Aprende con Zapo. Propuestas didácticas para el aprendizaje de competencias emocionales y sociales". The program aims to teach students with autism spectrum disorders facial expression recognition of basic and complex emotions (5 levels) and action prediction according to beliefs (true or false) (5 levels). The pupil interact with the main character (the clown Zapo) while performing the various tasks in the program so as to improve their understanding of social and emotional skills including the important skill of empathy [15].

Tanaka et al. (2008) designed "Let s Face It! Skills Battery (LFI! Battery)", a computer - based assessment, a series of interactive computer games, organized into a theoretical hierarchy of face processing domains that reinforce the child's ability to attend to faces, recognize facial identity and emotional expressions and interpret facial cues within a social context. The LFI! Battery was tested on participants with ASD and typically developing control (TDC) participants that were matched for age and IQ. Findings show that participants with ASD were able to label the basic facial emotions (with the exception of angry expression) on par with age- and IQmatched typically developing participants. This set of games aims reinforce the child's ability to attend to faces, recognize facial expressions and interpret facial cues in a social context. However, participants with ASD were impaired in their ability to generalize facial emotions across different identities and a tendency to recognize the mouth feature holistically and the eyes as isolated parts. The results also indicate that a relatively short-term intervention program can produce measurable improvements in the face recognition skills of children with autism [16], [17].

Golan et al. (2006) presented "Mind Reading", an interactive multimedia program developed to teach adults with Asperger syndrome and high-functioning autism about emotions and mental states. It is based on a taxonomic system of 412 emotions and mental states, clustered into 24 emotion groups, and six developmental levels from four years old to adulthood. Mind Reading uses video, audio and written text to systematically introduce and teach basic and complex emotions. Users were able to explore emotions in the emotion library, partake in lessons and quizzes in the learning center and play games about 
emotions in the game zone. Results showed that following 10-20 hours of using the software over a period of 10-15 weeks, users significantly improved their ability to recognize complex emotions and mental states from both faces and voices, when compared to their performance before the intervention and compared with a control group [18].

Silver and Oakes (2001) investigated the use of a multimedia software program, the Emotion Trainer, to teach individuals with ASD to recognize and anticipate emotions in others. The Emotion Trainer had five sections and utilized photographs of real people, as well as animated emotional expressions, to teach about emotions. Consistent feedback, prompting and reinforcement were provided and were contingent upon the level of success or difficulty an individual experienced while progressing through the program. It involves tasks focused on facial expression recognition, emotions prediction and interpretation based on context. Twenty-two individuals with ASD, ranging from ages 10 to18, were matched based on age, gender, and school class. One member of the pair was randomly assigned to the intervention condition of 10 computerized sessions over 2-3weeks, while the second member was placed in the no- intervention control condition. Both groups showed signi"cant improvements in the ability to identify emotion or mental state from photographs of facial expression from pre- to post-intervention [19].

Hughes (2014) designed a game called WUBeeS to aid young children with ASD (Autism Spectrum Disorder) in perspective taking and empathy by placing the player in the role of a caregiver to a virtual avatar. It is hypothesized that through the playing of this game over a series of trials, children with ASD will show an increase in the ability to discriminate emotions, provide appropriate responses to basic needs (e.g. feeding the avatar when it is hungry), and be able to communicate more clearly about emotions. Game data included response time to avatar needs, time spent playing incentive games, response to changes in emotional or physical expression of the avatar and other yet-to-be-determined game-play behavior [20].

Gotsis et al. (2010) described a novel game-based SST (Social Skills Training) intervention for ASD termed the Social Motivation Adaptive Reality Treatment Games (SMART-Games). The player manipulate an avatar in order to affect its moods, needs and behavior. The game emphasizes empathy and related social skills [21].

\section{B. Games for Health}

Cosgray et al. (1990) presented a simulation game called, "A Day in the Life of an Inpatient", to influence the attitude of staff toward those with mental illness. The game was designed so that staff could personally experience the situations sometimes experienced by psychiatric patients in a hospital. It was hoped that experience in the patient role would increase empathy of staff for patients, and that the experience would relate to positive changes. The game was designed to expose participants to specific staff approaches and rules/policies in the institution that could negatively affect patients. Results from 900 hospital staff indicated that the game raise staff sensitivity and staff with less patient contact felt more benefit [22].

McCallum et al. (2013) presented the educational game "Into D'mentia" by Ijsfontein. The game consists of a physical, interactive space where the world of a person with dementia is visualized using Virtual Reality and players are able to experience the limitations and obstacles that a dementia patient faces on his/her daily life. The game uses a simulation platform and it takes place inside a specifically customized truck. The goal of the game is to stimulate empathy for people with dementia and to raise awareness for the dicculties faced by these people [23], [24].

Brown et al. (1997) designed an interactive video game for health called "Packy and Marlon". The game is aimed at children with diabetes. The characters in the game are two elephants that are at a diabetes summer camp. They have to get rid of a gang of marauding rats that are keeping the campers from healthy food and diabetic supplies. To win, players have to successfully manage their insulin levels and food intake while keeping their characters' glucose levels within an acceptable range. This game was evaluated in a randomized trial in which participants in the treatment group played the game for 6 months (Brown et al., 1997). By the end of the study, patients who had access to the game showed greater perceived self-efficacy for diabetes self-management, increased communication with parents about diabetes, and improved daily diabetes self-management behaviors. Moreover the game can cultivate empathy for the patients of this chronic illness and the disease itself if "Packy and Marlon" is played by other people too [25].

Lieberman (2001) introduced "Bronkie the Bronchiasaurus", a video game that was made for young children with asthma. The game is set in prehistoric times and the world is covered in dust. A fan that usually keeps the dust at bay has broken. Players help the two in-game characters, Bronkie and Trakie, keep their asthma at bay by avoiding triggers such as dust and smoke while they go on their quest. There are some textual question-and-answer inserts in the game along the way that need to be answered correctly in order to proceed. A series of studies on the game found that patients' asthma-related self-concepts, social support, knowledge, self-care behaviors, and selfefficacy improved after playing the game compared with a control. Furthermore the game affect empathy, an important social skill [26].

Gerling et al. (2011) presented a game for health named "Cytarious" which aims to illustrate cancer treatment and to convey information about the disease through its background story and game mechanics. The background story is set in space and evolves around the four planets Haima, Enképhalon, Blaston and Cytarius. The inhabitants of Enképhalon and Haima live in peace but the inhabitants of Blaston have been excluded from the intergalactic community due to selfish behavior. To take revenge, they try to infiltrate the community by rapidly reproducing themselves and gaining control over the other planets. To defeat the intruders, the inhabitants of Cytarius - genetically engineered Cytowarriors who are leading by the player try to defend the two peaceful planets. The game engage patients and healthy children in play and beyond information about the disease it can develop empathic understanding to parents, medical staff and children [27].

Tate et al. (2009) created a video game called "ReMission" where the player enters the game world as nanobot which fights the disease from within young patients' bodies. The game aims to convey basic information about common cancer symptoms and treatment strategies through game mechanics, e.g. enemy and weapon design. "Re-Mission" tries to increase feelings of self-efficacy and 
self-esteem to the patients and evoke emotions and empathy for a better communication and interaction with the young patients [28], [29].

Rusch et al. (2011) presented "Elude", a single player game intended to inform friends and relatives of people with depression about what their loved ones are going through. Singapore-MIT GAMBIT Game Lab created Elude in order to help the patient's relatives to understand what it means to be depressive. "Elude's" metaphorical model for depression serves to bring awareness to the realities of depression by creating empathy with those who live with depression every day. The game takes place in a forest meant to represent a neutral mood. The goal is to climb trees until the tree tops where you reach "happiness". On the way the player will come up with different "passions" objects and must overcome the obstacles so as to make it to the tree tops and fly through the sky [30], [31].

Sherida Halatoe (Tiger \& Squid) developed "Beyond Eyes", a beautiful game about Rae, a blind girl who uses her remaining senses to visualize the world around her. Rae lost her eyesight in an accident and the experience left her traumatized. Fearing loud noises and public places, she hardly ever leaves her house. However, all that changes when her cat Nani unfortunately goes missing. The player must now guide Rae on her moving journey to be reunited with Nani, guard her from the dangers she may encounter along the way and learn her to overcome her fears and find beauty and possible new friends outside of her golden cage. Through this game experience the player feels empathetic for people with visual impairments and understands their behavior and actions better [32].

\section{CONCLUSIONS}

What is clear is that we live in an increasingly technological age and the influence of that technology is not just at a superficial level but pervades every aspect of our lives at a practical level but also at a more fundamental level of our very being. Exposure to ICT in some way contributed to raising the quality of life for the participants.

Empathy is an important social skill which should be developed in a small or a large extent to people. It allows us to interact in the social world and helps us become aware of many significant issues.

The articles reviewed above discussed the application of innovative computer games to assessment, intervention and cultivation of empathy to people with special educational needs and to people who have other health problems. In the first occasion pupils with disabilities lack of empathy and emotion recognition but by playing digital games could evoke these socioemotional skills with a playful manner. In addition, people with health problems find it also difficult to have empathy. But these games help as well people who have no health problems because they foster empathy to them in order to understand and feel the other people who are facing serious health problems.

Thus, while we can point to some encouraging research, more studies are needed to determine whether and how games can help develop empathy, the role of identification in building empathy, and whether empathy and identification are associated with increased interest in global learning. Games may be just one of many such avenues for this purpose, and towards this goal more games should be designed carefully to succeed in the growth of empathy. A consistent finding in the research literature is that empathy improves people's attitudes and behaviors towards other individuals or groups, while a lack of empathy is associated with more negative attitudes and behaviors.

To sum up, considering the enormous development of digital tools the review underlines that ICT tools do play a significant role in ensuring and enhancing empathy to achieve more in special education, in health, in human computer interaction etc.

\section{REFERENCES}

[1] McDonagh, D. (2006). Empathic research approaches to support the designer: a supra- qualitative research for designing model. Design Issues.

[2] Lipps, T. (1903). Einfühlung, innere Nachahmung und Organenempfindungen.

[3] Nilsson, P. (2003). Empathy and emotions: On the notion of empathy as emotional sharing.

[4] Gallo, D. (1989). Educating for empathy, reason and imagination. The Journal of creative behavior, 23(2), 98-115. http://dx.doi.org/10.1002/j.2162-6057.1989.tb00680.x

[5] Schuller, B., Marchi, E., Baron-Cohen, S., O'Reilly, H., Pigat, D., Robinson, P., \& Daves, I. (2014). The state of play of ASCInclusion: an integrated Internet-based environment for social inclusion of children with autism spectrum conditions. arXiv preprint arXiv:1403.5912.

[6] Boucenna, S., Narzisi, A., Tilmont, E., Muratori, F., Pioggia, G., Cohen, D., \& Chetouani, M. (2014). Interactive technologies for autistic children: a review. Cognitive Computation, 6(4), 722-740. http://dx.doi.org/10.1007/s12559-014-9276-x

[7] Alves, S., Marques, A., Queirós, C., \& Orvalho, V. (2013). LIFEisGAME Prototype: A Serious Game about Emotions for Children with Autism Spectrum Disorders. PsychNology Journal, 11(3), 191-211.

[8] Miranda, J. C., Sousa, A. A., Fernandes, T., \& Orvalho, V. C. (2011). Interactive technology: teaching people with autism to recognize facial emotions. INTECH Open Access Publisher.

[9] Beaumont, R., \& Sofronoff, K. (2008). A multi component social skills intervention for children with Asperger syndrome: The Junior Detective Training Program. Journal of Child Psychology and Psychiatry, 49(7), 743-753. http://dx.doi.org/10.1111/j.14697610.2008.01920.x

[10] Finkelstein, S. L., Nickel, A., Harrison, L., Suma, E., \& Barnes, T. (2009, March). cMotion: A new game design to teach emotion recognition and programming logic to children using virtual humans. In Virtual Reality Conference, 2009. VR 2009. IEEE (pp. 249-250). IEEE.

[11] Gibbons, S. (2015). Disability, Neurological Diversity, and Inclusive Play: An Examination of the Social and Political Aspects of the Relationship between Disability and Games. Loading..., 9(14).

[12] Social Clues. (2014). A curriculum based on 'evidence-based practices.' Social Clues. Retrieved from http://www.socialcluesgame.com/\#!science/c7jq

[13] Gerling, K. M., Mandryk, R. L., Birk, M. V., Miller, M., \& Orji, R. (2014, April). The effects of embodied persuasive games on player attitudes toward people using wheelchairs. In Proceedings of the SIGCHI Conference on Human Factors in Computing Systems (pp. 3413-3422). ACM. http://dx.doi.org/10.1145/2556288. $\underline{2556962}$

[14] Pivik, J., McComas, J., MaCfarlane, I., \& Laflamme, M. (2002). Using virtual reality to teach disability awareness. Journal of Educational Computing Research, 26(2), 203-218. http://dx.doi.org/10.2190/WACX-1VR9-HCMJ-RTKB

[15] Lozano, J., Ballesta, J., \& Alcaraz, S. (2011). Software for Teaching Emotions to Students with Autism Spectrum Disorder. Comunicar, 36, 139-148. http://dx.doi.org/10.3916/C36-2011-03-05

[16] Tanaka, J. W., Wolf, J. M., Klaiman, C., Koenig, K., Cockburn, J., Herlihy, L., ... \& Kaiser, M. D. (2012). The perception and identification of facial emotions in individuals with autism spectrum disorders using the Let's Face It! Emotion Skills Battery. Journal 


\section{GAMES FOR EMPATHY FOR SENSITIVE SOCIAL GROUPS}

of Child Psychology and Psychiatry, 53(12), 1259-1267. http://dx.doi.org/10.1111/j.1469-7610.2012.02571.x

[17] Wolf, J. M., Tanaka, J. W., Klaiman, C., Cockburn, J., Herlihy, L., Brown, C., ... \& Schultz, R. T. (2008). Specific impairment of face-processing abilities in children with autism spectrum disorder using the Let's Face It! skills battery. Autism Research, 1(6), 329-340. http://dx.doi.org/10.1002/aur.56

[18] Golan, O., \& Baron-Cohen, S. (2006). Systemizing empathy: Teaching adults with Asperger syndrome or high-functioning autism to recognize complex emotions using interactive multimedia. Development and psychopathology, 18(02), 591-617. http://dx.doi.org/10.1017/S0954579406060305

[19] Silver, M., \& Oakes, P. (2001). Evaluation of a new computer intervention to teach people with autism or Asperger syndrome to recognize and predict emotions in others. Autism, 5(3), 299-316. http://dx.doi.org/10.1177/1362361301005003007

[20] Hughes, D. E. (2014). The Design and Evaluation of a Video Game to Help Train Perspective-taking and Empathy in Children with Autism Spectrum Disorder (Doctoral dissertation, University of Central Florida Orlando, Florida).

[21] Gotsis, M., Piggot, J., Hughes, D., \& Stone, W. (2010, June). SMART-games: a video game intervention for children with $\mathrm{Au}-$ tism Spectrum Disorders. In Proceedings of the 9th International Conference on Interaction Design and Children (pp. 194-197). ACM. http://dx.doi.org/10.1145/1810543.1810569

[22] Cosgray, R. E., Davidhizar, R. E., Grostefon, J. D., Powell, M., \& Wringer, P. H. (1990). A day in the life of an inpatient: an experiential game to promote empathy for individuals in a psychiatric hospital. Archives of psychiatric nursing, 4(6), 354-359. http://dx.doi.org/10.1016/0883-9417(90)90025-G

[23] McCallum, S., \& Boletsis, C. (2013). Dementia Games: a literature review of dementia-related Serious Games. In Serious Games Development and Applications (pp. 15-27). Springer Berlin Heidelberg. http://dx.doi.org/10.1007/978-3-642-40790-1_2

[24] Into D'mentia: intodmentia.com, http://intodmentia.com/, (Last visited: April 5th, 2013)

[25] Brown, S. J., Lieberman, D. A., Gemeny, B. A., Fan, Y. C., Wilson, D. M., \& Pasta, D. J. (1997). Educational video game for juvenile diabetes: results of a controlled trial. Informatics for Health and Social Care, 22(1), 77-89.

[26] Lieberman, D. A. (2001). Management of chronic pediatric diseases with interactive health games: Theory and research findings. The Journal of ambulatory care management, 24(1), 26-38. http://dx.doi.org/10.1097/00004479-200101000-00004
[27] Gerling, K., Fuchslocher, A., Schmidt, R., Krämer, N., \& Masuch, M. (2011). Designing and evaluating casual health games for children and teenagers with cancer. In Entertainment ComputingICEC 2011 (pp. 198-209). Springer Berlin Heidelberg. http://dx.doi.org/10.1007/978-3-642-24500-8_21

[28] Tate, R., Haritatos, J., \& Cole, S. (2009). HopeLab's approach to Re-Mission.

[29] Kato, P. M., Cole, S. W., Bradlyn, A. S., \& Pollock, B. H. (2008). A video game improves behavioral outcomes in adolescents and young adults with cancer: a randomized trial. Pediatrics, 122(2), e305-e317. http://dx.doi.org/10.1542/peds.2007-3134

[30] Rusch, D. C. e-beratungsjournal. net.

[31] Singapore MIT GAMBIT Game Lab: Elude. http://gambit.mit.edu/loadgame/elude.php Last access 2012/03/29.

[32] http://www.tiger-squid.com/home/4558559479

\section{AUTHORS}

Athanasios Drigas is a Research Director at IIT, N.C.S.R. Demokritos. He is the Coordinator of Telecoms $\mathrm{Lab}$ and founder of Net Media Lab since 1996. From 1990 to 1999 he was the Operational manager of the Greek Academic network. He has been the Coordinator of Several International Projects, in the fields of ICTs, and eservices (e-learning, e-psychology, e-government, einclusion, e-culture etc). He has published more than 270 articles, 7 books, 25 educational CD-ROMs and several patents. He has been a member of several International committees for the design and coordination of Network and ICT activities and of international conferences and journals. Also he has accepted several distinctions for his work (articles, projects, patents) (e-mail: dr@iit.demokritos.gr).

Chara Papoutsi (MA in Applied Pedagogy) is a teacher in a primary school. She is also with NCSR DEMOKRITOS, Institute of Informatics and Telecommunications, Net Media Lab, Athens, Greece. (e-mail: xara.papoutsi@yahoo.com).

Submitted 08 June 2016. Published as resubmitted by the authors 13 August 2016 